\title{
Luminal Chloride Modulates Rat Distal Tubule Bidirectional Bicarbonate Flux In Vivo
}

David Z. Levine, David Vandorpe, and Michelle lacovitti

With the technical assistance of Virginia Harrison

Departments of Medicine and Physiology, University of Ottawa and Ottawa General Hospital, Ottawa, Ontario, Canada KH $8 M 5$

\begin{abstract}
The effects of replacing luminal chloride with gluconate on distal tubule bicarbonate transport were studied in vivo in normally fed rats, overnight-fasted rats, and rats made mildly alkalotic by administration of desoxycorticosterone acetate (DOCA). In paired microperfusions of the same tubule with 0 or $55 \mathrm{mM} \mathrm{Cl}$ at $25 \mathrm{nl} / \mathrm{min}$, net secretion of bicarbonate by distal tubules of fed rats was inhibited by chloride replacement. Zero chloride perfusion in DOCA rats also resulted in an inhibition of net bicarbonate secretion at $25 \mathrm{nl} / \mathrm{min}$. In contrast, replacement of $45 \mathrm{mM}$ chloride also perfused at $25 \mathrm{nl} / \mathrm{min}$ in fasted rats caused an increase in net bicarbonate reabsorption.

To further characterize the effects of changes in luminal chloride, experiments were undertaken in fasted rats with 0 , 45, and $100 \mathrm{mM}$ chloride-containing solutions perfused at 8 and $25 \mathrm{nl} / \mathrm{min}$. Perfusion with zero $\mathrm{Cl}$ resulted in net bicarbonate reabsorption at $8 \mathrm{nl} / \mathrm{min}$ that increased markedly with high flow, whereas bicarbonate reabsorption did not change significantly during perfusion at high flow with a $45-\mathrm{mM} \mathrm{Cl}$ perfusate. In marked contrast, perfusion with a $100-\mathrm{mM} \mathrm{Cl}$ solution resulted in only minimal bicarbonate reabsorption at 8 $\mathrm{nl} / \mathrm{min}$ with significant secretion observed at high flow.

Thus, chloride-free perfusates inhibit bicarbonate secretion and enhance bicarbonate reabsorption, while high chloride perfusates elicit net bicarbonate secretion in usually reabsorbing distal tubules. (J. Clin. Invest. 1990. 85:1793-1798.) acidbase $\bullet$ kidney $\bullet$ alkalosis $\bullet$ microperfusion
\end{abstract}

\section{Introduction}

McKinney and Burg (1) first showed that bicarbonate secretion could be demonstrated in the in vitro perfused cortical collecting duct of rabbits fed bicarbonate. Knepper et al. (2) subsequently reported a high rate of net bicarbonate secretion in cortical collecting tubules of rabbits receiving desoxycorticosterone acetate (DOCA), ${ }^{1}$ while Garcia-Austt et al. (3)

An abstract referring to a portion of this work has already appeared (1989. Clin. Res. 37:582A. [Abstr.]).

Address correspondence to Dr. D. Z. Levine, Department of Medicine, Health Sciences Building, 451 Smyth Road, Ottawa, Ontario, Canada, K1H 8M5.

Received for publication 2 November 1989 and in revised form 5 January 1990.

1. Abbreviations used in this paper: $\mathrm{BW}$, body weight; DOCA, desoxycorticosterone acetate.

J. Clin. Invest.

(c) The American Society for Clinical Investigation, Inc.

0021-9738/90/06/1793/06 \$2.00

Volume 85, June 1990, 1793-1798 showed that this secretion could be inhibited by chloride replacement. Subsequently, Star et al. demonstrated that a 1:1 $\mathrm{Cl}: \mathrm{HCO}_{3}$ exchange mechanism is the probable basis for these findings (4). Laski et al. (5) proposed that the transepithelial chloride gradient might alter proton secretion by changes in the $V_{\mathrm{TE}}$, or by influencing the apical $\mathrm{Cl}: \mathrm{HCO}_{3}$ exchanger.

Bicarbonate secretion in vivo was first reported by us in microperfused distal tubules of normally fed rats $(6,7)$, while Bichara et al. (8) have recently demonstrated bicarbonate secretion under free-flow conditions. The purpose of the present investigations was to determine if luminal chloride modulates in vivo bicarbonate transport by rat distal tubules. Our in vivo model of bidirectional bicarbonate transport allows us to change perfusate chloride concentration and assess separate effects of such changes on tubules that either secrete or reabsorb bicarbonate. The results indicate that chloride replacement arrests in vivo bicarbonate secretion in fed and DOCA alkalotic rats and augments bicarbonate reabsorption in distal tubules from overnight-fasted rats, and, with high chloride concentrations perfused at high flow, this reabsorptive flux can be transformed into net bicarbonate secretion.

\section{Methods}

These studies were performed on male Sprague-Dawley rats weighing $\sim 300 \mathrm{~g}$, bred and raised in a climate-controlled facility at the University of Ottawa. Fed animals were allowed free access to water and rat chow (5012; Ralston-Purina of Canada Ltd., Woodstock, Ontario, Canada) that contained $22 \%$ protein. Overnight-fasted animals were allowed water ad lib, but had no access to food for $16 \mathrm{~h}$ before the experiment. DOCA rats received an injection of $5 \mathrm{mg} / \mathrm{d}$ i.p. DOCA in an aqueous suspension (CSI Pharmaceuticals, Cherry Hill, NJ) for $3 \mathrm{~d}$, drank $150 \mathrm{mM} \mathrm{NaHCO} 3$ ad lib, and ate the same chow. DOCA rats were also injected with $5 \mathrm{mg}$ DOCA i.p. on the morning of the experiment. Rats were housed in individual metabolic cages that permitted urine collection for $16 \mathrm{~h}$ before the micropuncture experiment. Urine was collected under oil using thymol as a preservative.

Rats were anesthetized with $100 \mathrm{mg} / \mathrm{kg}$ Inactin (BYK Gulden, Konstanz, FRG) and were prepared for micropuncture as previously described $(6,7)$. All animals were infused with $0.5 \%$ body weight $(\mathrm{BW})$ of donor plasma followed by $1 \% \mathrm{BW} / \mathrm{h}$ of isotonic saline in fed and fasted groups and $2 \% \mathrm{BW} / \mathrm{h}$ isotonic saline in the DOCA group. The data derive from 106 collections obtained from 53 distal tubules.

Intratubular perfusion. Table I shows the perfusion solutions used. All perfusion solutions contained $0.05 \% \mathrm{FD}+\mathrm{C}$ green dye and were gassed with humidified $9 \% \mathrm{CO}_{2}, 91 \% \mathrm{O}_{2}$ to attain a $\mathrm{PCO}_{2}$ of $\sim 65$ $\mathrm{mmHg}$. All in vivo collections were quantitative and timed, and the concentration of $\left[{ }^{3} \mathrm{H}\right]$ inulin was determined in the initial perfusate and in the collected samples. In this way, significant departures from nominal perfusion rates were detected. In the present experiments in vivo perfusion rates were $7.9 \pm 0.2(n=31)$ and $24.5 \pm 0.3 \mathrm{nl} / \mathrm{min}$ $(n=75)$.

\section{Experimental design}

Perfusion of single distal tubules at the same flow rate with two solutions. To examine the effects of change in chloride delivery without 
Table I. Perfusion Solutions

\begin{tabular}{|c|c|c|c|c|c|c|c|c|}
\hline \multirow[b]{2}{*}{ Protocol } & \multicolumn{2}{|c|}{ Fed rats } & \multicolumn{2}{|c|}{ DOCA rats } & \multicolumn{4}{|c|}{ Fasted rats } \\
\hline & $1 \mathrm{~A}$ & 1B & $2 \mathrm{~A}$ & $2 B$ & $3 \mathbf{A}$ & $3 \mathrm{~B}$ & $5 \mathrm{~A}$ & $5 B$ \\
\hline $\mathrm{tCO}_{2}, \mathrm{mM}$ & 12 & 12 & 10 & 10 & 25 & 25 & 25 & 25 \\
\hline $\mathrm{Na}, m M$ & 65 & 65 & 61 & 61 & 68 & 68 & 123 & 123 \\
\hline $\mathrm{K}, m M$ & 2 & 2 & 1 & 1 & 2 & 2 & 2 & 2 \\
\hline $\mathrm{Cl}, \mathrm{mM}$ & 0 & 55 & 0 & 51 & 0 & 45 & 0 & 100 \\
\hline Urea, $m M$ & 0 & 0 & 18 & 18 & 0 & 0 & 0 & 0 \\
\hline $\begin{array}{l}\text { Gluconate, } \\
m M\end{array}$ & 55 & 0 & 51 & 0 & 45 & 0 & 100 & 0 \\
\hline $\begin{array}{l}\text { Osmolality, } \\
\text { mosmol/kg }\end{array}$ & 134 & 134 & 141 & 141 & 140 & 140 & 250 & 250 \\
\hline
\end{tabular}

All solutions contained $0.05 \%$ FD and $C$ green dye. Solutions for protocols $4 \mathrm{~A}$ and $4 \mathrm{~B}$ were identical to $3 \mathrm{~A}$ and $3 \mathrm{~B}$, respectively.

changing flow rate or bicarbonate load, distal tubules from the three groups of rats (DOCA, fed, and fasted) were perfused in a paired fashion (9) with both a chloride-containing and a zero chloride solution at $25 \mathrm{nl} / \mathrm{min}$ (Table I). Two Hampel nanoliter drive pumps were used for this procedure: the first loop of a double-looped surface distal tubule was punctured with a perfusion pipette containing one solution, then the first collection was made, and the perfusion pipette removed. The second perfusion was then performed with the second perfusion pipette in the same manner.

Perfusion of single distal tubules with the same solution at two flow rates. To assess the effects of luminal chloride on distal tubule bicarbonate reabsorption which occurs in fasted rats, single distal tubules were perfused at both 8 and $25 \mathrm{nl} / \mathrm{min}$ with a solution containing 0,45 , or $100 \mathrm{mM} \mathrm{Cl}$ (Table I). To reduce interanimal variability, we attempted to perfuse two tubules from each rat: one tubule was perfused with the $0 \mathrm{Cl}$ perfusate at 8 and $25 \mathrm{nl} / \mathrm{min}$, while another tubule was perfused with either 45 or $100 \mathrm{mM} \mathrm{Cl}$, also at both flow rates. Thus, data from fasted rats (protocol 4) include eight pairs of tubules from eight rats, while one tubule perfused with $0 \mathrm{Cl}$ was obtained from a rat that did not provide $45-\mathrm{mM} \mathrm{Cl}$ perfusions. In protocol 5 , six pairs of tubules were obtained from six rats, while two tubules perfused with $100 \mathrm{mM} \mathrm{Cl}$ were obtained from rats that did not provide $0 \mathrm{Cl}$ perfusions. Fig. 3 also shows these data, where results from two tubules in the same rats are plotted at 8 and $25 \mathrm{nl} / \mathrm{min}$.

\section{Analytical methods, statistical analyses, and calculations}

Total carbon dioxide concentration was measured by microcalorimetry (10). Particular care was taken to avoid loss of dissolved carbon dioxide: micropuncture pipettes and sample handling pipettes contained Hepes-buffered mineral oil and samples were placed on a quartz dish flooded with Hepes-buffered mineral oil. A separate tray contained four $\mathrm{NaHCO}_{3}$ standards $(5,10,15$, or $20 \mathrm{mM}$ for experiments with the $10-$ or $12-\mathrm{mM} \mathrm{NaHCO}_{3}$ perfusion solutions, or $10,20,30$, and $40 \mathrm{mM}$ for experiments with the $25 \mathrm{mM} \mathrm{NaHCO}_{3}$ perfusion solutions) in water-equilibrated mineral oil. A standard curve was run before sample analysis and standards bracketed the determination of the samples and perfusate $\mathrm{tCO}_{2}$ determinations.

Tubular fluid chloride concentrations were determined by electrotitration (Microtitre, model ET-1; WPI Inc., New Haven, CT) according to the method of Ramsay et al. (11). Briefly, $5 \mathrm{nl}$ of sample was deposited into a sulphuric acid bubble sitting on a silver wire under water-equilibrated oil. A current-passing electrode and a voltage-sensing electrode (made from pulled glass pipettes filled with $1 \mathrm{M} \mathrm{NaNO}_{3}$ in $2 \%$ agar and a small volume of $1 \mathrm{M} \mathrm{AgNO}_{3}$, fitted in acrylic microelectrode holders [WPI Inc.]) were inserted into the sample droplet. A constant current of known magnitude was applied to the droplet and the coulometric titration was followed by the electrometer probe to the preset endpoint voltage of $250 \mathrm{mV}$. The total charge of the sample was calculated by multiplying the titration time by the known current. A series of standards was run before and throughout the analysis to generate a regression line and assess instrument stability. For low chloride concentrations, a mid-curve chloride standard was added to the sample or perfusate before titration.

Other methods and calculations have already been detailed (6) except for the calculation of mean luminal chloride, which was taken as the arithmetic mean of the perfusate and collected chloride concentrations.

The statistical analyses included the paired $t$ test, unpaired $t$ test, analysis of variance, and regression analysis where appropriate (6). In Table II, significance figures were obtained by assessing the $t$ values with Bónferroni probabilities.

\section{Results}

\section{Whole animal data}

Fasted animals showed a significant reduction in plasma $\mathrm{tCO}_{2}$ concentration, blood $\mathrm{pH}$, and plasma [K] when compared with fed animals (Table II). In contrast to the other groups, fasted rats exhibited a significant decrease in body weight for the $16 \mathrm{~h}$ before the experiment. These changes and the pattern of urine electrolyte excretion in fed and fasted animals are similar to those previously reported (7). DOCA rats had significantly higher values for plasma $\mathrm{tCO}_{2}, \mathrm{pH}$, and urine $\mathrm{pH}$ than fed or fasted animals. Plasma [K] was significantly lower.

\section{Microperfusion data}

Perfusion with two solutions in the same tubule (protocols 1, 2, and 3). In protocols 1,2 , and 3 the effects of chloride replacement were studied at constant flow. Distal tubules from fed, DOCA, and overnight-fasted rats were perfused at $25 \mathrm{nl} / \mathrm{min}$ with either chloride-containing or zero chloride solution (see Table III and Fig. 1).

When perfused with $55 \mathrm{mM} \mathrm{Cl}$, tubules from the fed group secreted bicarbonate that was inhibited by perfusion with zero chloride $\left(\mathrm{JtCO}_{2}=-28 \pm 8\right.$ and $-2 \pm 9 \mathrm{pmol} \cdot \mathrm{min}^{-1} \cdot \mathrm{mm}^{-1}$, respectively, $P<0.001)$. Chloride flux changed from modest reabsorption to net secretion $\left(J_{\mathrm{Cl}}=16 \pm 50\right.$ to $-255 \pm 36$ $\mathrm{pmol} \cdot \mathrm{min}^{-1} \cdot \mathrm{mm}^{-1}$, respectively, $\left.P<0.005\right)$. In the fed group, four tubules were perfused with the chloride solution first and three with the zero chloride solution first. Fig. 1 also shows that tubules from DOCA-treated animals secreted bicarbonate at a high rate with $51 \mathrm{mM}$ chloride perfusion, which was changed to reabsorption with zero chloride $\left(\mathrm{JtCO}_{2}\right.$ $=-41 \pm 1 \dot{6}$ and $20 \pm 15 \mathrm{pmol} \cdot \mathrm{min}^{-1} \cdot \mathrm{mm}^{-1}$, respectively, $P$ $<0.0005)$. Chloride reabsorption was significantly different from zero in the DOCA group, which was also changed to net secretion by chloride replacement $\left(J_{\mathrm{Cl}}=243 \pm 41\right.$ and $-101 \pm 33 \mathrm{pmol} \cdot \mathrm{min}^{-1} \cdot \mathrm{mm}^{-1}$, respectively, $\left.P<0.0005\right)$. In the DOCA group four tubules were perfused with the chloride solution first and three tubules were perfused with the zero chloride solution first.

In contrast, fasted rats showed net bicarbonate reabsorption when perfused with $45 \mathrm{mM} \mathrm{Cl}$ perfusion, and this reabsorption was increased by $\mathrm{Cl}$ replacement $\left(\mathrm{JtCO}_{2}=37 \pm 13\right.$ to $67 \pm 7 \mathrm{pmol} \cdot \mathrm{min}^{-1} \cdot \mathrm{mm}^{-1}$, respectively, $\left.P<0.05\right)$. Net reabsorption of chloride was observed with $\mathrm{Cl}$ perfusion, which again changed to net secretion with chloride replacement $\left(J_{\mathrm{C}}\right.$ $=13 \pm 32$ and $-143 \pm 29 \mathrm{pmol} \cdot \mathrm{min}^{-1} \cdot \mathrm{mm}^{-1}$, respectively, $P$ $<0.0001$ ). 


\begin{tabular}{|c|c|c|c|c|c|c|c|}
\hline & $\begin{array}{l}\text { Fed (1) } \\
(n=6)\end{array}$ & $\begin{array}{c}\text { DOCA (2) } \\
(n=12)\end{array}$ & $\begin{array}{l}\text { Fasted (3) } \\
(n=12)\end{array}$ & $F$ & 1 vs. 2 & 1 vs. 3 & 2 vs. 3 \\
\hline \multicolumn{8}{|l|}{ Blood data } \\
\hline pH & $7.43 \pm 0.01$ & $7.47 \pm 0.01$ & $7.40 \pm 0.01$ & Sig. & 0.01 & 0.001 & 0.001 \\
\hline $\mathrm{PCO}_{2}(m m H g)$ & $44 \pm 1$ & $46 \pm 1$ & $44 \pm 1$ & NS & & & \\
\hline $\mathrm{HCO}_{3}$ (meq/liter) & $28.6 \pm 0.5$ & $33.0 \pm 0.8$ & $26.1 \pm 0.4$ & Sig. & 0.001 & NS & 0.001 \\
\hline $\mathrm{Na}$ (meq/liter) & $148 \pm 1$ & $148 \pm 1$ & $148 \pm 2$ & NS & & & \\
\hline $\mathbf{K}$ (meq/liter) & $5.0 \pm 0.1$ & $3.5 \pm 0.1$ & $4.3 \pm 0.1$ & Sig. & 0.001 & 0.001 & 0.001 \\
\hline $\mathrm{Cl}$ (meq/liter) & $104 \pm 1.0$ & $102 \pm 0.4$ & $106 \pm 1.0$ & Sig. & NS & NS & 0.01 \\
\hline Protein $(m g / d l)$ & $5.3 \pm 0.1$ & $4.8 \pm 0.1$ & $5.5 \pm 0.1$ & Sig. & 0.001 & NS & 0.001 \\
\hline$\Delta \mathrm{BW}(g)$ & $12.7 \pm 1.6$ & $6.9 \pm 1.3$ & $-23.4 \pm 1.3$ & Sig. & 0.05 & 0.001 & 0.001 \\
\hline \multicolumn{8}{|l|}{ Urine data } \\
\hline pH & $6.84 \pm .07$ & $8.12 \pm .04$ & $6.68 \pm .06$ & Sig. & 0.001 & NS & 0.001 \\
\hline $\mathrm{HCO}_{3}(\mu e q / 16 h)$ & $315 \pm 67$ & $5,576 \pm 705$ & $86 \pm 18$ & Sig. & 0.001 & NS & 0.001 \\
\hline $\mathrm{Na}(\mu e q / 16 h)$ & $2,204 \pm 201$ & $8,197 \pm 686$ & $559 \pm 65$ & Sig. & 0.001 & 0.001 & 0.001 \\
\hline $\mathrm{Cl}(\mu e q / 16 h)$ & $3,187 \pm 137$ & $2,130 \pm 133$ & $429 \pm 54$ & Sig. & 0.001 & 0.001 & 0.001 \\
\hline
\end{tabular}

$F, F$ statistic obtained by analysis of variance. $P$ values were obtained by $t$ test corrected by Bonferroni method. $\Delta$ BW, change in body weight for $16 \mathrm{~h}$ before experiment.

Perfusion at 8 and $25 \mathrm{nl} / \mathrm{min}$ with 0,45 , and $100 \mathrm{mM} \mathrm{Cl}$ in fasted rats (protocols 4 and 5; Tables I and III). We had hypothesized that in bicarbonate-secreting tubules, reduction of chloride load by perfusate chloride substitution caused a decrease in net bicarbonate secretion by reducing a unidirectional secretory flux. If true, then a decrease in net bicarbonate reabsorption in reabsorbing tubules from fasted rats might be demonstrated by increasing $\mathrm{Cl}$ delivery rates and increasing the unidirectional secretory flux. To test this proposition, tubules from overnight-fasted rats were perfused at 8 and 25 $\mathrm{nl} / \mathrm{min}$, with either 0,45 , or $100 \mathrm{mM} \mathrm{Cl}$ perfusate as shown in Table III and Fig. 2.

Perfusion with $45 \mathrm{mM} \mathrm{Cl}$ (protocol 4) resulted in significant bicarbonate reabsorption at $8 \mathrm{nl} / \mathrm{min}$ that tended to be diminished by perfusion at $25 \mathrm{nl} / \mathrm{min}\left(\mathrm{JtCO}_{2}=30 \pm 6\right.$ and $11 \pm 13 \mathrm{pmol} \cdot \mathrm{min}^{-1} \cdot \mathrm{mm}^{-1}$, respectively, $P>0.05$ ). In contrast, perfusion with $0 \mathrm{mM} \mathrm{Cl}$ resulted in significant bicarbonate reabsorption at $8 \mathrm{nl} / \mathrm{min}$ that increased further at $25 \mathrm{nl}$. $\min \left(J \mathrm{tCO}_{2}=40 \pm 4\right.$ and $72 \pm 15 \mathrm{pmol} \cdot \mathrm{min}^{-1} \cdot \mathrm{mm}^{-1}$, respectively, $P<0.05$; Fig. 3 ).

Since perfusion at $25 \mathrm{nl} / \mathrm{min}$ with $45 \mathrm{mM} \mathrm{Cl}$ reduced $\mathrm{JtCO}_{2}$, in contrast to the increase we reported with $26 \mathrm{mM} \mathrm{Cl}$ (6), we considered whether $100 \mathrm{mM} \mathrm{Cl}$ perfusate might further suppress the net reabsorptive flux (see above). Tubules perfused with $100 \mathrm{mM} \mathrm{Cl}$ (protocol 5) at $8 \mathrm{nl} / \mathrm{min}$ exhibited low rates of bicarbonate reabsorption that changed to net secretion at $25 \mathrm{nl} / \mathrm{min}\left(J \mathrm{tCO}_{2}=14 \pm 5\right.$ and $-23 \pm 8 \mathrm{pmol} \cdot \mathrm{min}^{-1} \cdot \mathrm{mm}^{-1}$, respectively, $P<0.05$ ). Thus, the $100-\mathrm{mM} \mathrm{Cl}$ perfusate elicited significant net $\mathrm{tCO}_{2}$ secretion in a setting where net reabsorption usually occurs. Table III shows that with the high osmolality perfusion solutions (5A and 5B), $J_{v}$ is significantly less ( $P$ $<0.01$ ) than with the $45-\mathrm{mM}$ chloride or gluconate solutions.

In this protocol, to decrease variability other tubules in the same kidneys were also perfused with a zero chloride solution matched for other constituents (Tables I and III). Mean $\mathrm{JtCO}_{2}$ at both 8 and $25 \mathrm{nl} / \mathrm{min}$ was significantly less when the tubule was perfused at $100 \mathrm{mM}$ chloride than when perfused at zero chloride $(P<0.01$ and 0.001 , respectively, by unpaired $t$ test; Fig. 3).

Net chloride secretion was observed with 0 chloride perfusion at $8 \mathrm{nl} / \mathrm{min}$ that increased at $25 \mathrm{nl} / \mathrm{min}\left(J_{\mathrm{Cl}}=-91 \pm 19\right.$ and $-201 \pm 50 \mathrm{pmol} \cdot \mathrm{min}^{-1} \cdot \mathrm{mm}^{-1}$, respectively, $P<0.05$ ). A small amount of chloride reabsorption is observed at low flow with 45-mM Cl perfusion that changes to secretion at high flow $\left(J_{\mathrm{Cl}}=34 \pm 27\right.$ and $-14 \pm 44 \mathrm{pmol} \cdot \mathrm{min}^{-1} \cdot \mathrm{mm}^{-1}$, respectively, $P>0.05)$. In contrast, perfusion with $100 \mathrm{mM} \mathrm{Cl}$ resulted in only net $\mathrm{Cl}$ reabsorption at both flows $\left(J_{\mathrm{Cl}}=163 \pm 21\right.$ and $156 \pm 43 \mathrm{pmol} \cdot \mathrm{min}^{-1} \cdot \mathrm{mm}^{-1}$, respectively, $P>0.05$ ).

\section{Mean luminal chloride concentrations}

Mean luminal chloride concentrations were calculated and are also given in Table III. On 50 pairs of data, stepwise linear regression analysis was carried out in a fashion that evenly represented values for $\mathrm{JtCO}_{2}$ at 0,45 , and $100 \mathrm{mM}$ chloride perfusion. Chloride load was the most significant predictor of $\mathrm{JtCO}_{2}(r=0.67, P<0.001)$. Correlation of mean luminal chloride concentration with $J \mathrm{tCO}_{2}$ was highly significant ( $P$ $<0.001, r=0.60$ ). Flow rate was not significantly correlated with $\mathrm{JtCO}_{2}$.

\section{Discussion}

\section{Luminal chloride and distal tubule bicarbonate secretion}

In vitro studies by McKinney and Burg (1) first demonstrated that cortical collecting tubules from bicarbonate-fed rabbits secrete bicarbonate, while in vivo microperfusion studies from our laboratory have demonstrated bicarbonate secretion in surface distal tubules from normally fed rats $(6,7)$. Knepper et al. (2) first reported that cortical collecting tubules from DOCA-treated rabbits secrete bicarbonate at a high rate, and Garcia-Austt et al. (3) subsequently showed that this secretion could be inhibited by luminal replacement of chloride. Evidence that a tight $\mathrm{Cl}: \mathrm{HCO}_{3}$ exchange process modulates bicarbonate secretion in this segment was provided by Star et al. (4), 
Table III. Summary of Microperfusion Data

\begin{tabular}{|c|c|c|c|c|c|c|c|c|c|c|}
\hline Protocol & $\begin{array}{l}\text { No. tubules/ } \\
\text { No. rats }\end{array}$ & $\begin{array}{l}\text { Tubular } \\
\text { length }\end{array}$ & $\begin{array}{l}\text { Perfusion } \\
\text { rate }\end{array}$ & $\begin{array}{l}\text { Perfusate } \\
\text { [Cl] }\end{array}$ & $\begin{array}{l}\text { Mean luminal } \\
\text { [C] }\end{array}$ & $\begin{array}{l}\text { Perfusate } \\
\left.\text { [tCO }{ }_{2}\right]\end{array}$ & $\begin{array}{c}\text { Collected } \\
{\left[\mathrm{tCO}_{2}\right]}\end{array}$ & $J_{v}$ & $J_{\mathfrak{a}}$ & $\mathrm{JtCO}_{2}$ \\
\hline & & $m m$ & $n l / \min$ & $m M$ & $m M$ & $m M$ & $m M$ & $\mathrm{nl} / \mathrm{min} \cdot \mathrm{mm}$ & $\mathrm{pmol} / \mathrm{min} \cdot \mathrm{mm}$ & $\mathrm{pmol} / \mathrm{min} \cdot \mathrm{mm}$ \\
\hline \multirow[t]{2}{*}{ 1. Fed rats } & $7 / 6$ & $1.3 \pm 0.1$ & 25 & 0 & $7.5 \pm 1.5$ & $11.0 \pm 0.2$ & $12.6 \pm 0.5$ & $2.4 \pm 0.4$ & $-255 \pm 36$ & $-2 \pm 9$ \\
\hline & & & 25 & 55 & $60.3 \pm 0.6^{*}$ & $11.5 \pm 0.3$ & $16.0 \pm 0.9$ & $3.3 \pm 0.7$ & $16 \pm 50$ & $-28 \pm 8^{*}$ \\
\hline \multirow[t]{2}{*}{ 2. DOCA rats } & $7 / 6$ & $1.3 \pm 0.1$ & 25 & 0 & $2.7 \pm 0.7$ & $10.2 \pm 0.4$ & $11.1 \pm 0.8$ & $3.7 \pm 0.5$ & $-101 \pm 33$ & $20 \pm 15$ \\
\hline & & & 25 & 51 & $50.0 \pm 1.3^{*}$ & $10.5 \pm 0.4$ & $16.8 \pm 0.9$ & $4.0 \pm 0.5$ & $243 \pm 41$ & $-41 \pm 16^{*}$ \\
\hline \multirow[t]{2}{*}{ 3. Fasted rats } & $8 / 6$ & $1.6 \pm 0.1$ & 25 & 0 & $5.1 \pm 0.8$ & $25.9 \pm 0.9$ & $27.9 \pm 1.0$ & $3.2 \pm 0.3$ & $-143 \pm 29$ & $67 \pm 7$ \\
\hline & & & 25 & 45 & $50.1 \pm 1.0^{*}$ & $25.9 \pm 0.9$ & $30.3 \pm 1.0$ & $3.3 \pm 0.4$ & $13 \pm 32$ & $37 \pm 13^{*}$ \\
\hline \multirow[t]{4}{*}{ 4. Fasted rats } & $9 / 9$ & $1.4 \pm 0.1$ & 8 & 0 & $10.8 \pm 1.4$ & $26.7 \pm 0.5$ & $31.3 \pm 0.9$ & $2.1 \pm 0.3$ & $-91 \pm 19$ & $40 \pm 4$ \\
\hline & & & 25 & & $6.4 \pm 1.2^{\S}$ & & $27.1 \pm 1.2$ & $2.7 \pm 0.5$ & $-201 \pm 50$ & $72 \pm 15^{8}$ \\
\hline & $8 / 8$ & $1.3 \pm 0.1$ & 8 & 45 & $56.5 \pm 1.5$ & $25.9 \pm 0.8$ & $39.0 \pm 2.9$ & $2.6 \pm 0.3$ & $34 \pm 27$ & $30 \pm 6$ \\
\hline & & & 25 & & $50.5 \pm 1.6^{8}$ & & $31.4 \pm 1.2$ & $3.4 \pm 0.4$ & $-14 \pm 44$ & $11 \pm 13$ \\
\hline \multirow[t]{4}{*}{ 5. Fasted rats } & $6 / 6$ & $1.6 \pm 0.1$ & 8 & 0 & $9.6 \pm 2.0$ & $26.5 \pm 0.3$ & $23.0 \pm 1.0$ & $0.8 \pm 0.0$ & $-87 \pm 22$ & $38 \pm 6$ \\
\hline & & & 25 & & $5.2 \pm 1.3^{\S}$ & & $24.1 \pm 1.2$ & $0.9 \pm 0.4$ & $-162 \pm 51$ & $61 \pm 15$ \\
\hline & $8 / 8$ & $1.4 \pm 0.1$ & 8 & 100 & $94.3 \pm 1.8$ & $26.0 \pm 0.4$ & $30.8 \pm 1.7$ & $1.1 \pm 0.0$ & $163 \pm 212$ & $14 \pm 5$ \\
\hline & & & 25 & & $98.3 \pm 1.5^{\S}$ & & $29.2 \pm 0.6$ & $1.0 \pm 0.0$ & $156 \pm 432$ & $-23 \pm 8^{\S}$ \\
\hline
\end{tabular}

Nominal chloride loads at $25 \mathrm{nl} / \mathrm{min}$ were $1,375,1,275,1,125,1,125$, and $2,500 \mathrm{pmol} \cdot \mathrm{min}^{-1}$, respectively, in protocols $1,2,3,4$, and $5 . * P$ $<0.05$ vs. perfusion with $0 \mathrm{Cl}$. ${ }^{\S} P<0.05$ vs. perfusion at $8 \mathrm{nl} / \mathrm{min}$. See text for other tests of significance.

and the kinetics of this exchanger have been further elucidated by Schuster (12), who reported that half-maximal rates of bicarbonate secretion were seen at luminal chloride concentrations of 4-11 mM.

We have previously reported that distal tubules of fed rats secrete bicarbonate when perfused at $25 \mathrm{nl} / \mathrm{min}^{2}$ with a 26-mM Cl solution (6). In this study we perfused distal tubules of fed rats with $55 \mathrm{mM} \mathrm{Cl}$ or $0 \mathrm{Cl}$ at $25 \mathrm{nl} / \mathrm{min}$ and showed that in every tubule net bicarbonate secretion is inhibited by chloride replacement, although in some tubules secretion persists, albeit at a lower rate. In DOCA-treated rats we also show that bicarbonate secretion is inhibited with zero chloride perfusion. Indeed, some tubules in the DOCA group showed brisk bicarbonate reabsorption when perfused with zero chloride (Fig. 1), suggesting that unidirectional bicarbonate reabsorption is unmasked by chloride replacement. This implies that net bicarbonate transport in rat distal tubules is the sum of opposing unidirectional fluxes. In view of this, we hypothesized that if the effects of zero chloride perfusion on net bicarbonate secretion is due to inhibition of the unidirectional secretory flux, then perfusing distal tubules from fasted rats with high chloride concentrations might reduce net bicarbonate reabsorption by stimulating the unidirectional secretory flux. This possibility was explored by perfusing reabsorbing distal tubules with 100 or $0 \mathrm{mM} \mathrm{Cl}$ at 8 and $25 \mathrm{nl} / \mathrm{min}$. Perfusion with $100 \mathrm{mM} \mathrm{Cl}$

2. Throughout the discussion, when we refer to perfusion at high flow, we wish the reader to recall that loads of chloride and bicarbonate are increased as well. showed that net bicarbonate reabsorption is converted to net secretion (Table III).

\section{Luminal chloride and distal tubule bicarbonate reabsorption}

Almost 30 years ago, perfusion with zero chloride solutions was reported to increase the $V_{\mathrm{TE}}$ of rat distal tubules (13). Insofar as proton secretion is thought to be an electrogenic process (14), this should increase bicarbonate reabsorption. In vitro studies of the cortical collecting duct, a part of the nephron sharing some of the same cell types as the latter part

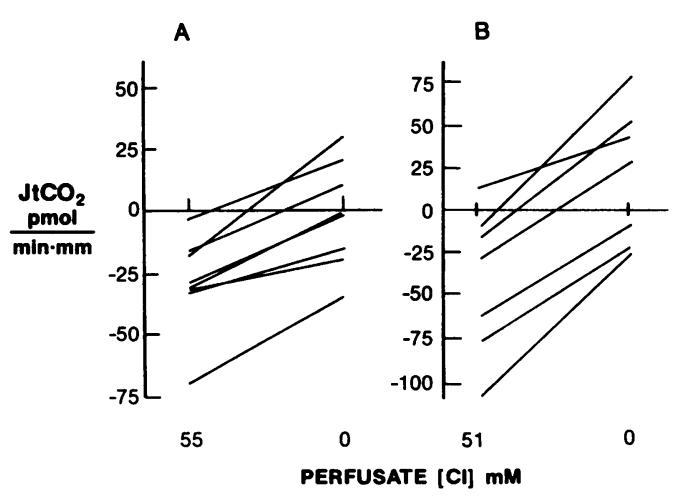

Figure 1. Distal tubule $J \mathrm{tCO}_{2}$ in fed $(A)$ and DOCA-treated rats $(B)$. Tubules were perfused at $25 \mathrm{nl} / \mathrm{min}$ with chloride-containing or zero chloride solutions. Means were significantly different by paired $t$ test, $P<0.001$. See Table III. 


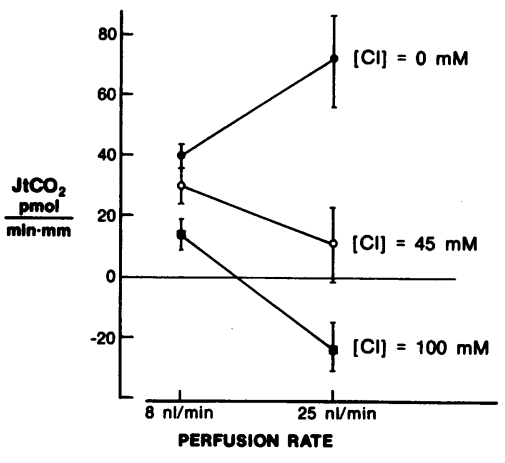

Figure 2. Distal tubule $\mathrm{JtCO}_{2}$ in fasted rats. Tubules were perfused at 8 and $25 \mathrm{nl} / \mathrm{min}$ with 0,45 , or $100 \mathrm{mM} \mathrm{Cl}$. See Results for signifcance tests.

of the surface distal tubule (15), have addressed this possibility. Laski and Kurtzman (16) found that replacement of luminal chloride with isethionate in rabbit cortical collecting tubules increased net bicarbonate reabsorption and suggested that this might occur via changes in the $V_{\mathrm{TE}}$ or in an apical $\mathrm{Cl}: \mathrm{HCO}_{3}$ exchanger. Laski and Kurtzman (16) have also reported that maintenance of the $V_{\mathrm{TE}}$ was a necessary concomitant of bicarbonate transport in cortical collecting ducts from starved rabbits: ouabain was shown to inhibit both the $V_{\mathrm{TE}}$ and $\mathrm{JtCO}_{2}$.

It was in this context that we undertook our evaluation of the effects of lumen chloride on bicarbonate reabsorbing distal tubules in vivo from overnight-fasted rats (7). When we perfused single distal tubules with solutions containing 45 or 0 $\mathrm{mM} \mathrm{Cl}$, we found that chloride replacement enhanced bicarbonate reabsorption (Fig. 2). We noted that the rate of bicarbonate reabsorption with the $45-\mathrm{mM} \mathrm{Cl}$ perfusate was less than in a previous study using a $26-\mathrm{mM} \mathrm{Cl}$ solution (6). This consideration led us to study the influence of larger chloride concentration differences $(0$ and $100 \mathrm{mM})$ by perfusing the tubule with the same solution at 8 and $25 \mathrm{nl} / \mathrm{min}$. Thus, in protocol 4 tubules were perfused with 0 or $45 \mathrm{mM} \mathrm{Cl}$ at 8 and $25 \mathrm{nl} / \mathrm{min}$, while in protocol 5 tubules were also perfused at both flow rates with 0 or $100 \mathrm{mM} \mathrm{Cl}$. The results show that bicarbonate reabsorption increases at high flow with $0 \mathrm{Cl}$, but decreases at high flow with $45 \mathrm{mM} \mathrm{Cl}$. Perfusion of tubules with $100 \mathrm{mM} \mathrm{Cl}$ at 8 and $25 \mathrm{nl} / \mathrm{min}$ results in suppression of $\mathrm{JtCO}_{2}$ at normal flow and elicits frank secretion at high flow, as already noted.

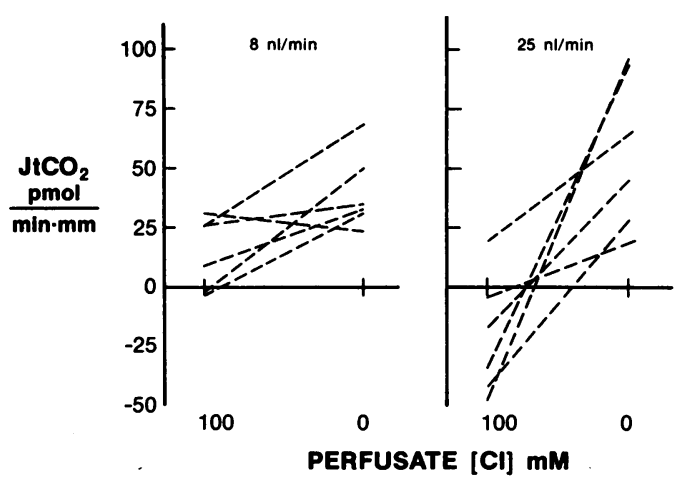

Figure 3. Distal tubule $\mathrm{JtCO}_{2}$ in fasted rats. Different tubules from the same rat were perfused with 0 or $100 \mathrm{mM} \mathrm{Cl}$ at 8 and $25 \mathrm{nl} / \mathrm{min}$. Mean $\mathrm{JtCO}_{2}$ was significantly increased by chloride replacement at both flow rates by unpaired $t$ test.

Possible mechanisms of modulation of net bicarbonate fluxes by luminal chloride

Perfusion with two solutions at constant flow. In our experiments we showed unequivocal suppression of bicarbonate secretion when perfusate chloride was replaced without altering flow (Fig. 1). Further, replacement of perfusate chloride led to enhanced reabsorption, also at constant flow (Table III). Thus, changes in flow are not sufficient to explain these findings. Rather, it is likely that perfusion with zero chloride per se leads to either suppression of net bicarbonate secretion or enhancement of net bicarbonate reabsorption by inhibiting the unidirectional bicarbonate secretory flux. This conjecture is supported by the mean luminal chloride concentrations, which are in the range of concentrations corresponding to the proposed $K_{\mathrm{m}}$ of the luminal $\mathrm{Cl}: \mathrm{HCO}_{3}$ exchanger (12).

Perfusion of one solution at two flow rates. The explanation for changes in net bicarbonate flux with different chloridecontaining solutions perfused at two flow rates is less evident. Sansom et al. (17) have shown that perfusate chloride replacement in the cortical collecting tubule of the rabbit results in a more negative $V_{\mathrm{TE}}$, which could alter proton secretion.

However, it is better to allow data from in vivo rat distal tubules to guide us in the formulation of mechanisms that may explain our results. Four such studies are relevant. First, Kunau and Walker (18) showed that $10^{-4} \mathrm{M}$ amiloride reduced distal tubule $V_{\mathrm{TE}}$ from -45 to $-4 \mathrm{mV}$, thereby reducing $J \mathrm{tCO}_{2}$ by $50 \%$. Second, Ellison et al. (19) showed that gluconate replacement of chloride was without effect on the $V_{\mathrm{TE}}$ of the in vivo perfused rat distal tubule. Third, Good and Wright (20) showed that increasing flow rate from 6 to $26 \mathrm{nl} / \mathrm{min}$ per se reduces $V_{\mathrm{TE}}$. Thus, these in vivo distal tubule perfusion studies strongly suggest that it is not the replacement of chloride, but rather the high flow rates, that suppress $J \mathrm{tCO}_{2}$ via a reduction in $V_{\mathrm{TE}}$. A fourth in vivo study indicates that increasing bicarbonate load elicits increases in $\mathrm{JtCO}_{2}$ in reabsorbing tubules (21). Taken together, these investigations support the view that with zero chloride perfusion the increase in $\mathrm{JtCO}_{2}$ we observe at high flow is caused by an increase in delivered bicarbonate load together with a suppression of the unilateral secretory flux by low chloride concentrations (see above). This occurs despite the possibility of a flow-induced reduction in $V_{\mathrm{TE}}$. On the other hand, the failure of $\mathrm{JtCO}_{2}$ to increase with high flow during perfusion with 45 or $100 \mathrm{mM} \mathrm{Cl}$ suggests that a continuing unilateral secretory flux, together with a decrease in $V_{\mathrm{TE}}$ that suppresses net bicarbonate reabsorption, more than offsets the influence of increases in bicarbonate load.

Why do we see secretion of bicarbonate at high flow with the $100-\mathrm{mM}$ but not with the $45-\mathrm{mM}$ chloride perfusate? It may be that very high luminal chloride concentrations and the high delivered chloride loads have some unanticipated effect to stimulate bicarbonate secretion other than via the $\mathrm{Cl}: \mathrm{HCO}_{3}$ exchanger. Another possibility is that the $100-\mathrm{mM} \mathrm{Cl}$ solution that results in the suppression of $J_{\mathrm{v}}$ due to its high osmolality, may in some fashion elicit the dissipation of a limiting alkaline boundary gradient.

Physiological significance of chloride modulation of distal tubule bicarbonate transport

Garcia-Austt et al. (3) have already provided an interpretation of the role for chloride in the regulation of bicarbonate handling. Galla and Luke (22) have reviewed their own important 
studies in which segmental chloride transport is related to the maintenance and correction of chloride depletion metabolic alkalosis, and have recently suggested (23) that during correction of chloride depletion metabolic alkalosis by administration of chloride, increased bicarbonate entry occurs at sites distal to the superficial distal tubule accessible to micropuncture. On the other hand, in a preliminary report Wesson and Babino (24) have implicated distal tubule chloride handling in the maintenance of chloride depletion metabolic alkalosis.

In conclusion, we have demonstrated for the first time that net bicarbonate transport in the microperfused distal tubule in vivo can be modulated by luminal chloride in normally fed, overnight-fasted, and DOCA alkalotic rats. Bicarbonate secretion is arrested by perfusion with zero chloride solutions. Bicarbonate reabsorption in overnight-fasted rats is enhanced when chloride is absent from the perfusate. Most striking is the demonstration of net bicarbonate secretion during perfusion with high chloride loads in tubules that previously show brisk bicarbonate reabsorption.

\section{Acknowledgments}

Important suggestions were made by Drs. Steven Nadler, Linda Peterson, and Fred Wright. We are grateful to Dr. Peterson and Janet Borzecki for help with the chloride method. Mrs. Phyllis Morrissey cheerfully typed the manuscript.

\section{References}

1. McKinney, T. D., and M. B. Burg. 1977. Bicarbonate transport by rabbit cortical collecting tubules. Effect of acid and alkali loads in vivo on transport in vitro. J. Clin. Invest. 60:766-768.

2. Knepper, M. A., D. W. Good, and M. B. Burg. 1984. Mechanism of ammonia secretion by cortical collecting ducts of rabbits. Am. J. Physiol. 247:F729-F738.

3. Garcia-Austt, J., D. W. Good, M. B. Burg, and M. A. Knepper. 1985. Desoxycorticosterone-stimulated bicarbonate secretion in rabbit cortical collecting ducts: effects of luminal chloride removal and in vivo acid loading. Am. J. Physiol. 249:F205-F212.

4. Star, R. A., M. B. Burg, and M. A. Knepper. 1985. Bicarbonate secretion and chloride absorption by rabbit cortical collecting ducts. Role of chloride/bicarbonate exchange. J. Clin. Invest. 76:1123-1130.

5. Laski, M. E., D. G. Warnock, and F. C. Rector, Jr. 1983. Effects of chloride gradients on total $\mathrm{CO}_{2}$ flux in the rabbit cortical collecting tubule. Am. J. Physiol. 244:F112-F121.

6. Iacovitti, M., L. A. Nash, L. N. Peterson, J. Rochon, and D. Z. Levine. 1986. Distal tubule bicarbonate accumulation in vivo. Effect of flow and transtubular bicarbonate gradients. J. Clin. Invest. 78:1658-1665.
7. Levine, D. Z., M. Iacovitti, L. A. Nash, and D. Vandorpe. 1988. Secretion of bicarbonate by rat distal tubules in vivo. Modulation by overnight fasting. J. Clin. Invest. 81:1873-1878.

8. Bichara, M., O. Mercier, P. Houillier, M. Paillard, and F. Leviel. 1987. Effects of antidiuretic hormone on urinary acidification and on tubular handling of bicarbonate in the rat. J. Clin. Invest. 80:621-630.

9. Good, D. W., and F. S. Wright. 1979. Luminal influences on potassium secretion, sodium concentration and fluid flow rate. Am. J. Physiol. 236:F192-F205.

10. Vurek, G. G., D. G. Warnock, and R. Corsey. 1975. Measurement of picomole amounts of carbon dioxide by calorimetry. Anal. Chem. 47:765-767.

11. Ramsay, J. A., R. H. J. Brown, and P. C. Croghan. 1955. Electrometric titration of chloride in small volumes. J. Exp. Biol. 32:822-829.

12. Schuster, V. L. 1986. Cyclic adenosine monophosphate-stimulated anion transport in rabbit cortical collecting duct. J. Clin. Invest. 78:1621-1630.

13. Clapp, J. R., F. C. Rector, Jr., and D. W. Seldin. 1962. Effect of unreabsorbed anions on proximal and distal transtubular potentials in rats. Am. J. Physiol. 202:781-786.

14. Steinmetz, P. R. 1986. Cellular organization of urinary acidifcation. Am. J. Physiol. 251:F173-F187.

15. Verlander, J. W., K. M. Madsen, and C. C. Tisher. 1987. Effect of acute respiratory acidosis on two populations of intercalated cells in rat cortical collecting duct. Am. J. Physiol. 253:F1142-F1 156.

16. Laski, M. E., and N. Kurtzman. 1983. Characterization of acidification in the cortical and medullary collecting tubule of the rabbit. J. Clin. Invest. 72:2050-2059.

17. Sansom, S. C., E. J. Weinman, and R. G. O'Neil. 1984. Microelectrode assessment of chloride-conductive properties of cortical collecting duct. Am. J. Physiol. 247:F291-F302.

18. Kunau, R. T., Jr., and K. A. Walker. 1987. Total $\mathrm{CO}_{2}$ absorption in the distal tubule of the rat. Am. J. Physiol. 252:F468-F473.

19. Ellison, D. H., H. Velazquez, and F. S. Wright. 1985. Stimulation of distal potassium secretion by low lumen chloride in the presence of barium. Am. J. Physiol. 248:F638-F649.

20. Good, D. W., and F. S. Wright. 1980. Luminal influences on potassium secretion: transepithelial voltage. Am. J. Physiol. 239:F289-F298.

21. Capasso, G., P. Jaeger, G. Giebisch, V. Guckian, and G. Malnic. 1987. Renal bicarbonate reabsorption in the rat. II. Distal tubule load dependence and effect of hypokalemia. J. Clin. Invest. 80:409414 .

22. Galla, J. H., and R. G. Luke. 1988. Chloride transport and disorders of acid-base balance. Annu. Rev. Physiol. 50:141-158.

23. Galla, J. H., D. N. Bonduris, and R. G. Luke. 1989. Superficial distal and deep nephrons in correction of metabolic alkabosis. Am. J. Physiol. 257:F107-F113.

24. Wesson, D. E., and H. Babino. 1988. Correlation of distal nephron chloride handling with maintenance and correction of Cl-deplete chronic metabolic alkalosis in rats. Clin. Res. 36:30A. (Abstr.) 